\title{
Demonstration of CD44 gene expression in cells from fine needle aspirates of breast lesions by the polymerase chain reaction
}

\author{
J Bolodeoku, K Yoshida, P Yeomans, C A Wells, D Tarin
}

\begin{abstract}
Aim-To demonstrate the feasibility of studying specific gene expression in fine needle aspirates from clinical lesions. The reverse transcription/polymerase chain reaction (RT-PCR) technique was used to demonstrate CD44 gene expression in cells from diagnostic fine needle aspirates taken from patients attending the outpatient clinic for breast diseases.

Methods-Polyadenylated RNA was extracted from the cells remaining in the syringe barrel after fine needle aspirate cytological diagnosis of 41 patients with breast lesions. Analysis of CD44 gene expression was performed by RT-PCR using primers flanking the site for insertion of the variant exons. The resulting products were separated on $1 \cdot 2 \%$ agarose gels, transferred to nylon membranes using Southern blotting and hybridised with specific probes for standard (constitutive) and variant exons of this gene.
\end{abstract}

Results-On hybridisation with the CD44 standard exon probe, the expected amplified product of approximately 482 base pairs was visualised in 22 of 41 samples examined. Further hybridisation with the "variant" exon probes (exons 7 (v2), 8 (v3), $9 b(v 4), 12$ (v7), and 15 (v10)) on 12 of these samples showed the presence of large molecular variants in all of these samples. However, the expression pattern detected with the probes for exons 7 (v2), 8 (v3) and $9 \mathrm{~b}$ (v4) differed among the patients.

Conclusions-Expression of the standard and variant regions of the CD44 gene in cells remaining in the syringe after fine needle aspiration was demonstrated using RT-PCR. The $5^{\prime}$ variant exon probes seemed to show different patterns of expression among the patients. Further studies are currently being conducted to determine whether there is any correlation between expression of the various components of this gene and cytological diagnosis. Using this method, it would be possible to study the expression of other candidate marker genes in breast cancer using fine needle aspirates.

(f Clin Pathol: Mol Pathol 1995;48:M307-M309)

Keywords: CD44, fine needle aspirates, breast cancer.
The potential of DNA technology to enhance the diagnostic power of fine needle aspiration cytology has been proposed recently. ${ }^{12}$ Cytopathological evaluation of breast lesions using fine needle aspiration is one of the main methods of obtaining a preoperative tissue diagnosis, as it is a much quicker, simpler technique which is less painful and requires no anaesthetic compared with wide bore needle or other biopsy procedures. Fine needle aspiration sometimes has the drawback of being able to provide only a limited amount of specimen, but the high sensitivity of the polymerase chain reaction (PCR) can usually facilitate genetic analyses when this is the case. Examples of this include the amplification of DNA for human papilloma virus sequences in metastatic squamous cervical cell tumours and the identification of $\mathrm{K}$ ras gene mutations in pancreatic masses using fine needle aspirates. ${ }^{2-4}$ We have previously described the use of the reverse transcription/ polymerase chain reaction (RT-PCR) for the analysis of overexpression and abnormal splicing of mRNA transcripts from the CD44 gène in snap frozen breast cancer tissue and compared this with the corresponding normal tissue. ${ }^{5}$ Recently, abnormal expression of the CD44 gene has been shown to be of prognostic value in breast cancer ${ }^{67}$ and the opportunity of obtaining such information at the time of initial diagnosis could be attractive clinically. The aim of this study was to determine the feasibility of analysing gene expression in cells obtained from fine needle aspirates using RT-PCR. The samples consisted of residual cells left in the syringe after the appropriate cytological specimens had been obtained from patients attending the outpatient clinic.

\section{Methods}

Routine diagnostic smears were made from the fine needle aspirates of 41 patients attending the outpatient clinic, and the cells remaining in the barrel of the syringe after cytological diagnosis were resuspended in cell culture medium and centrifuged at $1500-2000 \mathrm{rpm}$ for five minutes. The supernatant was decanted and the pellet stored in liquid nitrogen until used. Polyadenylated RNA was extracted using the Micro-fast Track mRNA extraction kit (Invitrogen); the kit permits the isolation of 
PolyA + mRNA directly from cells. The cells were lysed in a detergent based buffer containing protein degrader, incubated at $45^{\circ} \mathrm{C}$ and directly applied to oligo (dT) cellulose for absorption. Non-polyadenylated RNA, DNA, dissolved membranes, and cellular debris were washed off the resin with high and low salt buffer. The polyadenylated RNA was eluted from the resin in the absence of salt. cDNA synthesis was catalysed by SUPERSCRIPT II reverse transcriptase (Gibco BRL). The first strand synthesis was primed with oligo (dT) and CD44 cDNA was specifically amplified using Taq polymerase and primers $\mathrm{Pl}$ and P4. ${ }^{5}$ Then, $15 \mu \mathrm{l}$ of the PCR products was electrophoresed in $1.2 \%$ agarose gel; the gels were stained with ethidium bromide, viewed under ultraviolet light, and then subjected to Southern blot transfer onto Hybond-N + nitrocellulose paper with $0.4 \mathrm{~N} \mathrm{NaOH}$ solution overnight. The filters were hybridised with $\mathrm{CD} 44 \mathrm{~s}$ (standard) and CD44v (variants) v2, $\mathrm{v} 3, \mathrm{v} 4^{8}, \mathrm{v} 7$, and $\mathrm{v} 10$ exon specific probes. The probes were amplified using PCR from a cloned genomic CD44 template (c2311) containing all the variant exons. ${ }^{8}$ The PCR conditions for generating the probes were as follows: $94^{\circ} \mathrm{C}$ for five minutes and $85^{\circ} \mathrm{C}$ for one minute, after which the Taq polymerase was added. Then,
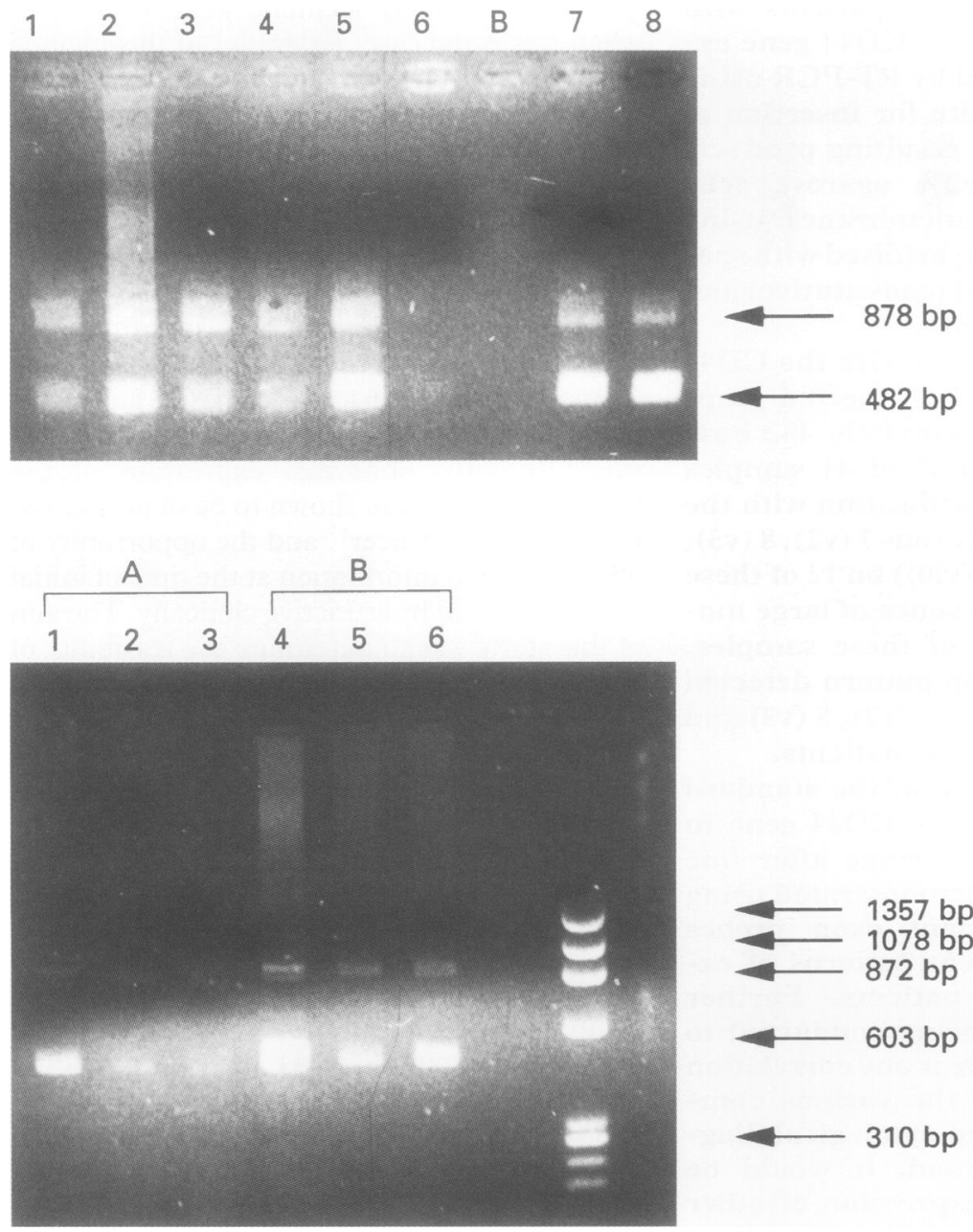

Figure 1 Results of RT-PCR amplification of RNA extracted from aspirated cells from eight patients, using primers $P 1$ and $P 4$ seen on an ethidium bromide stained agarose gel (top panel). $B=$ unloaded track. The bottom panel shows results of RT-PCR amplification of RNA from three fine needle aspirates $(A)$ and three fresh frozen breast tissue samples (B).
35 cycles were performed as follows: $94^{\circ} \mathrm{C}$ for one minute, $55^{\circ} \mathrm{C}$ for one minute and $72^{\circ} \mathrm{C}$ for two minutes.

The sequences of the primers used for the amplification of CD44 transcripts in the clinical samples were as follows: P1: 5'-GACACATATTGCTTCAATGCTTCAGC-3'; P4: 5'GATGCCAAGATGATCAGCCATTCTGGAA- $3^{\prime}$. The sequences of the primers for generating the probes for Southern blot analysis of $\mathrm{CD} 44 \mathrm{~s}$ and $\mathrm{v}$ expression were as follows: CD44s probe-P2: 5'-CCTGAAGAAGATTGTACATCAGTCACAGAC and A15: 5'-ACTGGGGTGGAATGTGTCTTGGTC-3'; exon 7 (v2): E1: 5'-TTGATGAGCACTAGTGCTACAGCA-3', E2: 5'-CATTTGTGTTGTTGTGTGAAGATG-3'; exon 9b (v4): EX8: 5'-TCAACCACACCACGGGCTTTTGAC3', AEX8: 5'-AGTCATCCTTGTGGTTGTCTGAAG-3'; exon 12 (v7): E3 5'-AGCCCAGAGGACAGTTCCTGG-3'， E5: 5'-TCCTGCTTGATGACCTCGTCCCAT-3'; exon 15 (v10): SD5: 5'-GATGTCACAGGTGGAAGAAGAGAC-3', D5: 5'-TTCCTTCGTGTGTGGGTAATGAGA-3'.

The probes were labelled with ECL nucleic acid labelling reagents (Amersham, Little Chalfont, UK) according to the manufacturer's instructions and the filters were hybridised overnight. The filters were washed with $0.4 \%$ SSC $/ 0.5 \%$ SDS solution three times for 10 minutes. Hybridisation was detected using the enhanced chemiluminescence system (ECL detection system; Amersham) on $x$ ray films (Kodak). ${ }^{9}$

\section{Results and Discussion}

If sufficient high quality RNA can be obtained from a specimen, the RT-PCR technique using primers $\mathrm{P} 1$ and $\mathrm{P} 4$ results in an amplified product of 482 base pairs if the cells are transcribing only the standard constitutively expressed portion of the CD44 gene. ${ }^{5}$ Larger amplicons will be produced if the cells in the specimen contain alternatively spliced transcripts. In tissues containing epithelial cells some of the abundant transcripts are the epithelial forms which are recognised as one or more bands of greater than 870 base pairs on electrophoretic gels. ${ }^{10}$ Figure 1 (upper panel) shows an ethidium bromide stained gel of PCR products of cells from eight fine needle aspirates. All but one (patient 6) of these specimens showed products of about 482 and 878 base pairs; in the exception there is only a faint 482 base pair band indicating either that the specimen contained fewer cells or that the RNA had degraded. To confirm that the amplified products we produced were similar to those seen in intact breast tissue, we amplified RNA extracted from fresh frozen breast tissue using the same protocol and ran the products alongside the products of the fine needle aspirates. Figure 1 (lower panel) shows the PCR products obtained from three fine needle aspirates (A) and from three fresh frozen breast tissue samples (B) when amplified using the P1/P4 primers. The CD44s product of 482 base pairs and some other fragments larger than 872 base 
Exon 7 (v2)

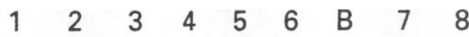

\section{Exon 7 (v)}

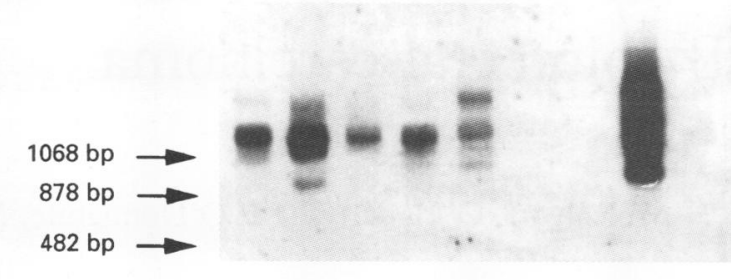

Exon 8 (v3)

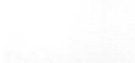

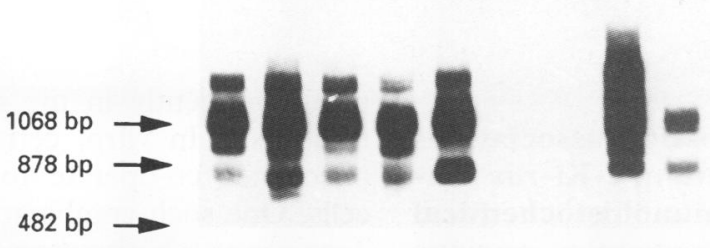

Exon $9 b(v 4)$

Exon 9 (v)

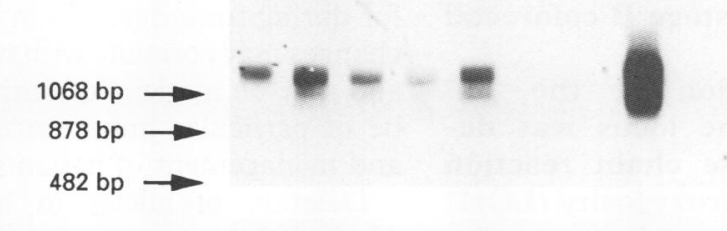

Exon $12(v 7)$

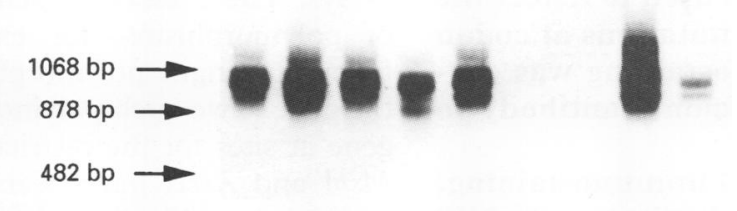

Exon $15(v 10)$

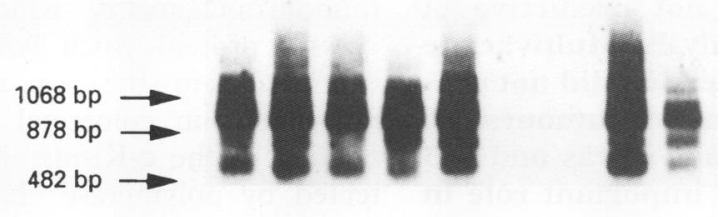

CD44 s probe

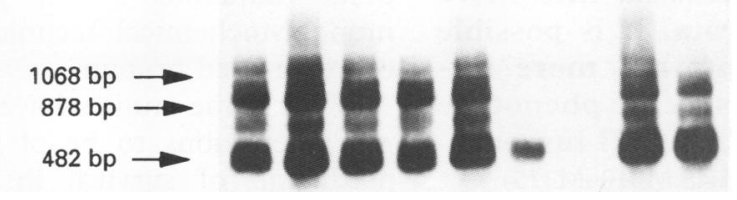

Figure 2 Southern blot analysis of PCR amplified products from eight human breast fine needle aspirates. The PCR products were resolved in $1.2 \%$ agarose, transferred to a Hybond $N+$ membrane and analysed by hybridisation with ECL labelled probes as described previously. ${ }^{8}$

pairs can be seen in both the fine needle aspirates and solid frozen tissue samples.

In this study 22 of the 41 specimens examined showed a strong hybridisation signal with the standard CD44 probe. The results of Southern blot hybridisation of the gel shown in fig 1 with CD44 standard and variant exon probes are shown in fig 2. The same filter was stripped and rehybridised with each probe separately. Using the CD44s probe, the 482 base pair product was seen in all the samples. In patient 6 there was a very low hybridisation signal compared with those seen in all the others, suggesting that there was very little sample present initially. The hybridisation signals obtained with probes for CD44 exons 7, 8 and 9 (v2, 3 and 4) showed different patterns of expression among samples from different patients. These differences involved the size, intensity and number of the transcripts present, and were most obvious with the CD44 exon 7 (v2) probe. In one patient (no. 8) there was no expression of exon 7 (v2) nor of exon $9 \mathrm{~b}(\mathrm{v} 4)$. However, this patient expressed exons 8, 12 and $15(\mathrm{v} 3, \mathrm{v} 7$ and v10) as shown by the strong hybridisation signal with the appropriate probes. Patients 1 and 7 were found histologically and cytologically to have adenocarcinoma and the remainder had benign disease. We are currently conducting more extensive studies to evaluate these expression patterns in relation to the pathological diagnosis in these patients.

In conclusion, we have succeeded in using the RT-PCR method to demonstrate the expression of the standard and variant exons of the CD44 gene in the cells left in the aspirating syringe, after routine smears had been made for diagnosis. We have shown that this technique can be used to analyse gene expression in fine needle aspirates of breast lesions and it may serve as a potentially useful adjunct to routine cytopathological diagnosis.

We thank Mrs L Summerville for invaluable help in the preparation of the manuscript.

This work was partly supported by a research contract between Boehringer Mannheim GmbH and Oxford University.

1 Buley ID. Update on special techniques in routine cytopathology. F Clin Pathol 1993;46:881-5.

2 Ihalainen J, Taavitsainen M, Salmivaara T, Palotie A. Diagnosis of pancreatic lesions using fine needle aspirant cytology: Detection of K-ras point mutations using solid phase minisequencing. F Clin Pathol 1994;47:1082-4.

3 Shibata D, Cosgrove M, Arnheim A, Martin WJ, Martin SE. Detection of human papillovirus DNA in fine needle aspirations of metastatic squamous cell carcinoma of the aspirations of metastatic squamous cell carcinoma of the
cervix using the polymerase chain reaction. Diagn Cytocervix using the polym
pathol 1989;5:40-3.

4 Shibata D, Almoguera C, Forrester K, Dunitz J, Martin $\mathrm{SE}$, Cosgrove MM, et al. Detection of c-K-ras mutations in fine needle aspirates from human pancreatic adenocarcinomas. Cancer Res 1990;50:1279-83.

5 Matsumura Y, Tarin D. Significance of CD44 gene products for cancer diagnosis and disease evaluation. Lancet 1992; 340: $1053-8$.

6 Joensuu H, Klemi PJ, Toikkanen S, Jalkanen S. Glycoprotein CD44 expression and its association with survival in breast cancer. Am f Pathol 1993;143:867-74.

7 Kaufman M, Heider K-H, Sinn H-P, von Minckwitz G, Ponta H, Herrlich P. CD44 variant exon epitopes in Ponta H, Herrlich P. CD44 variant exon epitopes in
primary breast cancer and length of survival. Lancet 1995; 34:615-19.

8 Matsumura Y, Sugiyama M, Matsumura S, Hayle AJ, Robinson P, Smith JC, et al. Unusual retention of introns in CD44 gene transcripts in bladder cancer provides new diagnostic and clinical oncological opportunities. $\mathcal{F}$ Pathol 1995;177:11-20.

9 Matsumura Y, Hanbury D, Smith J, Tarin D. Non-invasive detection of malignancy by identification of unusual CD44 gene activity in exfoliated cancer cells. BMF 1994;308: 619-24.

10 Finn L, Dougherty G, Finley G, Meisler A, Beciech M, Cooper DL. Alternative splicing of CD44 pre-mRNA in Cooper DL. Alternative splicing of CD44 pre-mRNA in
human colorectal tumours. Biochem Biophys Res Commun 1994;200:1015-22. 